\title{
A tentativa biográfica: o desafio de escrever parte da vida de Cyro Martins
}

\author{
The biographical attempt: the challenge of writing part of the life of Cyro Martins
}

Fábio Varela Nascimento

Pontifícia Universidade Católica do Rio Grande do Sul, Porto Alegre, Rio Grande do Sul, Brasil

$\diamond$

\begin{abstract}
Resumo: Este artigo se relaciona ao tema da prática biográfica. O projeto Cyro Martins os anos decisivos (1908-1951) se desenvolve no Programa de Pós-Graduação em Letras da Pontifícia Universidade Católica do Rio Grande do Sul, na área de Teoria da Literatura, desde o ano de 2014. Em "A tentativa biográfica": o desafio de escrever parte da vida de Cyro Martins, as origens do trabalho são esclarecidas, a relação entre biógrafo e biografado é destacada, os espaços de pesquisa e as escolhas do biógrafo são evidenciados. Além disso, textos de alguns estudiosos da biografia são recuperados (Leon Edel, François Dosse, Anna Caballé, José Castello) e a organização da tentativa biográfica Cyro Martins - os anos decisivos (1908-1951) é apresentada.
\end{abstract}

Palavras-chave: Biografia; Cyro Martins; Desafio

\begin{abstract}
This article is related to the biographical practice subject. The project Cyro Martins - the decisive years (1908-1951) is developed in the Programa de Pós-Graduação em Letras, in Pontifícia Universidade Católica do Rio Grande do Sul, in the area of Theory of Literature, since the year 2014. In "The biographical attempt": the challenge of writing part of the life of Cyro Martins, the origins of the work are clarified, the relationship between biographer and biographer is highlighted, the research spaces and biographer's choices are evidenced. In addition, texts of some scholars of the biography are recovered (Leon Edel, François Dosse, Anna Caballé) and the organization of the biographical attempt Cyro Martins - the decisive years (1908-1951) is presented.
\end{abstract}

Keywords: Biography; Cyro Martins; Challenge

Nunca encontrei o Cyro Martins em carne e osso. Quando ele faleceu em Porto Alegre, em dezembro de 1995, depois de ter vivido por mais de 87 anos, eu me preparava para a formatura da pré-escola. Havia grandes distâncias e descaminhos entre nós. Por causa deles, não tive noção de como ele era alto, não percebi o tom rosado de suas faces e não ouvi sua voz macia. O Cyro que encontrei tempos depois se manifestava por palavras impressas, fotografias, documentos e livros. Não sei precisar o momento em que ouvi seu nome pela primeira vez. Não sei precisar, nem mesmo, o dia em que o conheci. Pode ter sido em uma das minhas idas à biblioteca do Colégio Estadual Frei Getúlio, lá em Bom Jesus, ou em uma das visitas às estantes 51 e 52 do $3^{\circ}$ andar da Biblioteca Central da Pontifícia Universidade Católica do Rio Grande do Sul (PUCRS). Em algum desses lugares o conheci, mas não foi em nenhum dos dois que Cyro atravessou a minha vida. O encontro também não se deu em abril de 2009, data em que ingressei, como bolsista de Iniciação Científica, no Delfos - Espaço de Documentação e Memória Cultural da PUCRS. Não trabalhei no seu acervo e o meu contato com Cyro se resumia a breves olhadas para seu espólio, de segunda-feira a sexta-feira, das $14 \mathrm{~h}$ às $17 \mathrm{~h}$. O encontro decisivo ocorreu em um dia do inverno de 2010, quando, no mesmo Delfos, vi a lombada de um dos seus romances: Gaúchos no obelisco. Um título daqueles só poderia se referir à Revolução de 1930. Se falasse daquela revolução, falaria de Getúlio Vargas e costuraria literatura e história.

$\mathrm{Na}$ época, eu me preocupava com uma monografia que envolvia justamente Vargas, a literatura e a história. Tratava de Erico Verissimo e de alguns episódios de 
$O$ arquipélago, mas qualquer leitura que se aproximasse do tema despertava a minha atenção. Li Gaúchos no obelisco, vi o que pretendia e muito mais. Não havia como analisar o romance naquele final de graduação. No entanto, se fosse possível, faria um estudo maior, uma dissertação. Com a entrada no curso de Mestrado em Teoria da Literatura do Programa de Pós-Graduação em Letras da PUCRS, em 2012, veio a oportunidade e defendi, no início de 2014, a dissertação intitulada Literatura e história em "Gaúchos no obelisco", de Cyro Martins.

O resultado do Mestrado foi menos interessante do que o seu percurso. Desde o início do curso, eu tinha a ideia de ler toda a produção de Cyro e os textos de outros autores que demonstrassem abordagens biográficas. Não era possível descartar a biografia de Cyro de alguns dos episódios presentes em Gaúchos no obelisco. Quando jovem, ele participou como voluntário do movimento revolucionário e, na obra, havia referências ao próprio Cyro, pois devia ser o Cyro de quase 22 anos que assistia, com Aureliano de Figueiredo Pinto, à procissão em que Vargas, então candidato à presidência da república pela Aliança Liberal, desfilava ao lado do bispo metropolitano; devia ser o Cyro de 22 anos completos que testemunhava, de um vão de porta da Rua da Praia, os acontecimentos daquele final da tarde de 3 de outubro de 1930; também devia ser o Cyro estudante de Medicina que, em um dia de verão entre 1932 e 1933, falava para um certo Bilo, no interior de São João Batista do Quaraí, sobre as barbaridades do governo Flores e a ascensão de regimes fascistas na Europa.

Em Gaúchos no obelisco, no seu município e no seu distrito, aquele Bilo teve papel relevante na composição da Frente Única Gaúcha. Aquele mesmo Bilo que se sacrificou para mandar os filhos estudarem em Porto Alegre já fora importante para a narrativa de Sombras na correnteza (1979) e para as articulações dos assisistas de 1922 e de 1923. O Bilo que correu atrás de escola para os seus guris e os da vizinhança em $O$ professor (1988) carregava não só o apelido de Appolinário Martins, o pai de Cyro, mas também as suas opções políticas, suas qualidades e seus defeitos.

A busca pela formação aparecia nos escritos de Cyro com a mesma recorrência que a figura de Bilo. Em um momento, o Carlos, de Mensagem errante (1942), com menos de 12 anos, era o guri mandado para estudar com os padres em um Ginásio de Porto Alegre; em outro, o jovem era um "doutorando" pobre de medicina que vagueava por pensões baratas, matava a fome com laranjas de umbigo e se apaixonava pela literatura; na sequência, ele era um médico recém-formado que lutava para se readaptar à vida interiorana e buscar seu espaço profissional. As histórias do aluno interno do colégio dos jesuítas, do aspirante a médico e do médico iniciante apresentavam incríveis semelhanças com a história de vida de Cyro. Quando me dedicava ao Gaúchos no obelisco, eu já percebia tais semelhanças, mas elas não me perturbavam até que li algumas afirmações da contracapa de Para início de conversa (1990). Nas letras pretas colocadas sobre um fundo azul-claro, Cyro disse que pensava lhe faltar "gabarito para escrever memórias" e que achava não ter "assunto para mais de uma dúzia de páginas". Ele parecia querer fugir de uma das ideias que Georges Gusdorf expôs em Les ecritures du moi (1991): um autor com a proposta de escrever suas memórias é, por essência, um importante, que tenta fazer com que ele mesmo e outras pessoas se convençam da importância dos papéis que ele desempenhou ao longo da vida. Ao se considerar um incapacitado para criar tal tipo de texto, Cyro tirava de si essa importância e ainda se vestia com os trajes da modéstia.

Porém, como Cyro podia falar aquilo? Ele não tinha espalhado suas memórias por aqueles livros já citados e em outros como Rodeio - estampas e perfis (1976) e A dama do saladeiro (1980)? Ao falar de Sombras na correnteza e Gaúchos no obelisco não se considerou uma "testemunha da história" (MARTINS; SLAVUTZKY, 1990, p. 58)? Não falou dos amigos da literatura - Alcides Maya, Augusto Meyer, Aureliano de Figueiredo Pinto, João Octávio Nogueira Leiria, Dyonélio Machado, Lila Ripoll, Erico Verissimo - e dele mesmo em Escritores gaúchos (1981)? Não vivenciou os acontecimentos de boa parte do século XX? Cyro sabia que era um importante. Ele tinha assunto para dúzias de páginas e muitas delas já estavam publicadas. Naquele 1990, Cyro chegara aos 82 anos e seu nome estava mais do que consolidado tanto na área da psicanálise quanto na da literatura produzida no Rio Grande do Sul. Em seu currículo, constavam 25 livros - divididos entre ficção, ensaios literários e ensaios científicos. Não lhe faltavam gabarito nem experiência para escrever suas memórias, pois ele fazia isso havia tempos e tinha muitas histórias para contar.

Para início de conversa foi uma obra construída a quatro mãos, entre 1987 e 1989. Abrão Slavutzky, amigo e colega de profissão de Cyro, fazia perguntas relacionadas à vida, à literatura, à psicanálise e o entrevistado ficava à vontade para respondê-las da maneira que bem entendesse - ou não responder. É claro que Cyro deixou muitos temas pessoais de lado (relações com a mãe, com a primeira mulher e com os filhos), mas falou sobre o período de formação que aparecia em Um menino vai para o colégio e em A dama do saladeiro, sobre os testemunhos das revoluções de 1923 e 1930, sobre a tentativa de dar sobrevida ao pai em várias de suas narrativas ficcionais.

Eu tinha material suficiente para desenvolver uma dissertação sobre Gaúchos no obelisco e o envolvimento 
de Cyro na Revolução de 1930. No entanto, eu já estava envolvido demais com as leituras que circundavam a vida daquele autor e, se tivesse chances, iria mais fundo. O ideal seria encontrar um texto biográfico que não fosse contado e editado pelo próprio Cyro. Não demorei a ter contato com um trabalho desse tipo. Cyro Martins - 100 anos: o homem e seus paradoxos foi escrito por dois jornalistas, Celito De Grandi e Nubia Silveira e publicado em 2008, ano das comemorações referentes ao centenário de Cyro. De Grandi e Silveira poderiam ter percebido e dito algo sobre o biografado deixar suas memórias e os pedaços de sua história espalhados por diversos livros. Os autores só tocaram no assunto quando se aproximavam do final das mais de duzentas páginas do livro e o que eles afirmaram não me convenceu: "Afora os depoimentos a Abrão, em Para início de conversa, pouco escreveu sobre si" (DE GRANDI; SILVEIRA, 2008, p. 194). Marquei a frase em vermelho e coloquei um NÃO ao lado. O não era o advérbio apropriado para o momento. Eu não concordava com a ideia dos biógrafos e não queria continuar por aquele caminho. A dissertação que envolvia Gaúchos no obelisco se mostrava mais difícil e trabalhosa do que eu imaginara e seria melhor não desviar o foco. Aqueles pedaços de memória tinham de ficar para outra hora.

Em janeiro de 2014, o Mestrado terminou e, no mesmo ano, em março, ingressei no curso de Doutorado em Teoria da Literatura da PUCRS. No processo seletivo para o Doutorado, era necessário que um projeto de tese fosse apresentado e eu não tinha dúvidas de que havia chegado a hora de fazer um trabalho mais abrangente sobre a obra de Cyro Martins. Eu pretendia colocar em um projeto os pedaços de memória que Cyro espalhou pelos seus escritos, pretendia utilizar livros e outros materiais guardados no Delfos. Pensava em reconstruir o percurso leitor do jovem Cyro e, para isso que isso acontecesse, investigaria os rastros deixados por ele. Com esses rastros, restos do passado conforme a ideia de Paul Ricoeur (2010, p.212), eu poderia refigurar o tempo e fazer aparecer o caminho das leituras que mexeram com a cabeça do futuro escritor e psicanalista. O projeto não era de todo ruim e até apresentava certa originalidade, mas eu não sabia se ele tinha potencial para tese ou dissertação. Talvez fosse mais produtivo expandir o projeto e contemplar tanto um período maior da vida do autor quanto uma gama maior de sua obra.

Se era possível, através dos rastros, recuperar as leituras que Cyro fez na juventude, também era possível recuperar todo o período de formação, das primeiras letras no Cerro do Marco à especialização psicanalítica em Buenos Aires, a maturidade como profissional e escritor brigando pelo seu lugar ao sol, a velhice como figura reconhecida na literatura e na psicanálise. Se era possível escrever sobre uma época da vida de Cyro e de um aspecto de sua vida intelectual, era possível escrever sobre sua vida inteira.

Antes de me aventurar na tentativa de criar uma biografia, levantei uma importante pergunta: por que Cyro Martins? Ele já estava na minha vida. O personagem me fascinava e eu queria entendê-lo melhor; queria perceber o porquê de escrever tanto sobre alguns aspectos de sua vida e tão pouco sobre outros; queria compreender o porquê de focalizar o pai e apagar a mãe e os irmãos; queria entender o porquê de afirmar que não tinha gabarito para escrever memórias e preferir falar dos outros a falar de si quando falava muito de si; queria ler as ausências e os não ditos; queria preencher incômodas lacunas.

Preencher lacunas é apenas uma das ideias que François Dosse mostra em $O$ desafio biográfico: escrever uma vida (2015). Ele também fala em construir a narrativa possível de uma vida; na relação entre o eu do biógrafo com o outro, o biografado; na necessidade de o biógrafo expor suas intenções e as "motivações que o levaram a acompanhar a vida do biografado e retraçar-lhe a carreira" (2015, p. 95); na obrigação de não descentralizar o herói da biografia; na utilização de memórias, confissões e outros registros de cunho autobiográfico que possam tentar reconstituir de forma mais autêntica o passado do biografado; em articular vida e obra - no caso da biografia intelectual - sem reducionismos e separações estanques; em conhecer os lugares do biografado.

Ao se referir à impureza do gênero biográfico, Dosse (2015, p. 55) lembra que, nesse tipo de trabalho, além do compromisso com a cronologia, com as fontes, com os acontecimentos e com as expectativas do leitor, é inevitável o recurso à ficção, pois, sem ela, "não se pode restituir a riqueza e a complexidade da vida real". Desse modo, o biógrafo não desempenha só o papel de pesquisador, historiador, jornalista, detetive e crítico, ele ainda precisa "refazer um universo perdido segundo sua intuição e talento criador" (DOSSE, 2015, p. 55). Assim, a imaginação e a criação têm importante papel no preenchimento das lacunas e dos lapsos que envolvem uma vida.

Preencher, construir, articular e criar são verbos que já carregam, em seu tom, o desafio. Cyro Martins e as questões que sua figura suscitam valem a tentativa de conjugação desses verbos e o desafio biográfico.

Além das razões de cunho pessoal, havia outras. Em primeiro lugar, estava a relevância do biografado no cenário intelectual sul-rio-grandense e a necessidade de olhá-lo mais detidamente. Por outro lado, o acervo de Cyro Martins fora cedido à PUCRS e guardado no Delfos para que se tornasse fonte de estudos. O espólio do escritor só se mantém "vivo" e ganha significado através das pesquisas. A larga produção de Cyro também não 
era iluminada em vários pontos. A Trilogia do gaúcho a pé, formada por Sem rumo (1937), Porteira fechada (1944) e Estrada nova (1954), fez o nome do autor na área da literatura, recebeu, e continua recebendo, a maioria dos holofotes nos trabalhos que compõem a sua fortuna crítica. Uma análise que abrangesse toda a produção de Cyro poderia colocar pelo menos um pouco de luz sobre os livros e textos que foram deixados de lado.

Outra pergunta que surgia frente ao desafio biográfico estava ligada ao seu valor acadêmico: a biografia de Cyro Martins era uma tese, um trabalho científico com aceitação na academia? Nas palavras de Anna Caballé, encontrei uma boa reflexão:

[...] la posibilidad de estructurar la vida humana a partir de los datos y fuentes disponibles [...] ubicarla en su época y en las encrucijadas personales que le tocó vivir es un ejercicio que exige una formidable competencia intelectual. Si ese esfuerzo va acompañado de una rigurosa mención de las fuentes utilizadas, de una sólida bibliografia y de un estado de la cuestión que permita definir la aportación realizada, no se entiende muy bien el rechazo acadêmico que todavía despierta. (CABALLÉ, 2015, s/p.)

Realizada com rigor, a biografia não estaria distante dos trabalhos acadêmicos e a proposta de elaborá-la no Doutorado em Teoria da Literatura, especificamente na linha de pesquisa Literatura, História e Memória, não se mostrava descabida. O projeto foi aceito no Programa de Pós-Graduação em Letras da PUCRS, recebeu apoio do Conselho Nacional de Desenvolvimento Científico e Tecnológico - CNPq - e a orientação da Doutora Maria Eunice Moreira.

Em 2015, cumpridos os requisitos solicitados pelo Programa, iniciei a tentativa biográfica. No primeiro semestre daquele ano, a Doutora Anna Caballé Masforroll, coordenadora da Unidade de Estudos Biográficos da Universidade de Barcelona, passou um período como professora visitante no PPGL-PUCRS. Entre diferentes atividades, ela ministrou a disciplina Escrita Memorialística Contemporânea, na qual foram abordados temas como as memórias, a autobiografia, a biografia e o diário íntimo. Participei das aulas como ouvinte e, por interferência de minha orientadora, pudemos nos reunir com a professora Anna Caballé. Nessas ocasiões, tive orientações sobre o processo da escrita biográfica ${ }^{1}$.

Depois de conversas com as professoras Maria Eunice e Anna Caballé, alguns pontos foram estabelecidos. Durante a pesquisa, persigo a seguinte questão: por que um homem que não se considerava

\footnotetext{
No final de 2015, o PPGL-PUCRS autorizou que a professora Anna Caballé fosse considerada coorientadora do trabalho.
}

uma figura importante e digna de memórias se esforçou tanto para ser importante - importante na psicanálise, importante na literatura? Essa é a principal pergunta, mas outras vêm atrás dela. Como se deu a formação de Cyro? Como foram os períodos vividos no internato do Anchieta, na Faculdade de Medicina? Como iniciou a sua escrita? O que lia? Com que grupos de amigos se envolveu? Quais eram seus posicionamentos políticos? Como a morte prematura do pai afetou sua vida e sua produção? Qual foi a marca deixada pela prática médica feita no interior, pouco depois de sua formatura? Por que a relação com a mãe e os irmãos foi tão apagada? Como lidou com os traumas do primeiro casamento? Como se inseriu no sistema literário do Rio Grande do Sul? Por que não assumia sua produção autobiográfica? Por que exaltou certas dificuldades e deixou outras de lado? Qual foi sua contribuição para a psicanálise gaúcha? Como era a relação com familiares, amigos, editores e críticos?

Para tentar responder a essas interrogações, percorro espaços de pesquisa como: o Delfos, a biblioteca do Colégio Anchieta, os arquivos da Faculdade de Medicina de Porto Alegre, do Núcleo de Pesquisa em História da Universidade Federal do Rio Grande do Sul (UFRGS) e do jornal Correio do Povo, o Hospital Psiquiátrico São Pedro, a casa paroquial da Igreja Matriz de Quaraí e o Cemitério Jardim da Saudade, localizado na mesma cidade. Os livros publicados por Cyro, a fortuna crítica que envolve sua obra, os depoimentos e os textos sobre o autor também são utilizados.

Não há nenhuma novidade em contar que o planejado entre 2014 e 2015 se modificou nos dois anos seguintes. Isso é comum em muitos projetos e com uma biografia não seria diferente. É claro que, para a mudança de planos, a inexperiência do biógrafo teve grande contribuição. Eu imaginava que em sete grandes capítulos, em um total de 250 páginas, a vida de Cyro Martins estaria contada até com sobras e floreios. Foi um equívoco da minha parte. Uma vida não se resume a algumas centenas de páginas. Com Cyro não seria diferente. O trabalho ganhou proporções maiores e aquilo que foi imaginado não cobriu metade dos 87 anos de Cyro. Os leitores mais críticos diriam que o biógrafo subestimou o biografado, subestimou a complexidade de uma existência. A afirmação seria justa e acertada se não fosse vista por outro prisma: o biógrafo superestimou sua capacidade para lidar com os fatos que preencheram a existência do biografado.

Com essa alteração de planos e a necessidade de defender a tese no período de quatro anos, o que era para ser uma biografia de toda a vida de Cyro Martins sofreu um recorte. Optei por escrever sobre o período que vai de 1908 a 1951, uma época que considero decisiva para os futuros caminhos de Cyro. Nesse arco temporal, o biografado fez boa parte de sua formação e tanto suas 
escolhas profissionais quanto literárias foram tomadas - ele se inclinou para a psicanálise e dois dos seus três livros mais conhecidos foram publicados. Além disso, no tocante à vida familiar, Cyro passou por episódios marcantes: o falecimento repentino do pai, o primeiro casamento, o nascimento de duas filhas, a separação da primeira mulher, o segundo casamento. Entendo o fato de um leitor de biografias se interessar pelo conjunto de uma existência, de querer saber o que se passa desde o abrir das cortinas até a última cena do ato final. Não foi essa a minha escolha - e o biógrafo tem a obrigação de fazer escolhas. Acredito que, mesmo abordando apenas 43 anos da vida do biografado, o trabalho possui alguma relevância e apresenta condições de integrar o corpo de estudos que envolve a figura de Cyro Martins e a sua produção.

Virginia Woolf (2007, p. 195) disse que uma vida, "incluso cuando se trata de un sacerdote, no es sino una serie de hazañas" e a sentença não carregava nada de absurdo. Como se lida com a vida alheia? Como se mede a importância dos fatos passados? Com que olhos se observam as atitudes de um sujeito? Como se julgam as ações de um homem ou de uma mulher? Durante a escrita da biografia de Cyro Martins, considerei todos os episódios recuperáveis importantes. Não era irrelevante se, na juventude, ele tivesse publicado textos de alguns parágrafos em revistas efêmeras. $\mathrm{O}$ acontecimento interessava por mostrar que, de alguma forma, ele tentava fazer parte do círculo, tentava publicar e ser lido. Não era irrelevante se ele trocava de endereço de tempos em tempos. Deveria haver razões para isso - principalmente financeiras. Entretanto, dar relevância a todos os episódios resgatáveis também pode ser uma tarefa diabólica. Por um lado, esse modo de proceder busca valorizar cada passo do indivíduo, conferindo significado às pequenas vitórias $\mathrm{e}$ às pequenas derrotas que constroem um caminho. Por outro, sufoca o candidato a biógrafo. Quando teria fim uma biografia que se detém em cada conquista e a cada tropeço? Os anos de um curso de Doutorado seriam suficientes para refigurar uma vida? Não posso responder por outros, mas, para mim, não.

Em "Carta a um jovem biógrafo", José Castello, autor de Vinicius de Moraes: o poeta da paixão - uma biografia (1994), falou sobre sua experiência. Para ele (2001, p. 52), desde o início, a aventura biográfica está "fadada à decepção e ao fracasso". "Fadada" é uma palavra de carga semântica forte e, por isso, não concordo plenamente com a opinião. Penso que a empreitada está sujeita a diversos percalços e, em muitos casos, a decepção e o fracasso se impõem. Contudo, nada impede a satisfação e o sucesso. Naturalmente, Castello fez o comentário partindo de sua visão, de sua tentativa biográfica (bem-sucedida, aliás, indicada como finalista do Prêmio Jabuti em 1995) e isso é compreensível. Fazendo o mesmo - partindo de minha tentativa -, eu diria que há boas chances de a decepção ocorrer em alguma curva do caminho biográfico.

Diversos aspectos rodeiam a escrita de uma biografia: a condição das fontes, a organização dos estabelecimentos de pesquisa, as barreiras acadêmicas, a disponibilidade dos entrevistados, a preparação do candidato a biógrafo. A decepção pode se esconder em cada um desses aspectos. Na minha tentativa biográfica, acredito que a preparação do biógrafo desencadeou uma série de outras decepções. Linhas atrás, fiz referências à superestimação da capacidade do biógrafo e às mudanças que os planos iniciais sofreram. A superestimação já era um indício de desapontamento e outros se seguiram.

No começo da jornada, eu não tinha reunido todo o material disponível a respeito de Cyro e, com o tempo, isso se mostrou um erro grave. Eu conhecia alguns itens que compunham o acervo do autor, principalmente a sua biblioteca, mas isso não me garantia domínio sobre todos os materiais. Apesar de ser rico em livros, documentos, originais e fotografias, o acervo não contava com quantidade relevante de correspondências pessoais e os diários eram inexistentes por Cyro não se inclinar a tal prática. Tanto as cartas quanto os diários seriam (e aqui faço um exercício positivo de imaginação) reveladores de uma faceta mais "íntima" de Cyro - como se relacionava com a mãe, a noiva, os irmãos, os sogros, os amigos. $\mathrm{Na}$ ausência de papéis que fornecessem pistas acerca de um Cyro Martins privado, restava direcionar as esperanças as entrevistas com familiares e amigos. No entanto, desde que surgiu a ideia da biografia de Cyro Martins, imaginei que esse seria meu maior ponto de dificuldade.

Quando falo dessa dificuldade, não transfiro a responsabilidade. Não culpo o processo do Comitê de Ética da Universidade para aprovar a lista dos prováveis entrevistados - a pesquisa lidava com seres humanos e, mesmo que eu não fizesse experimentos, não estivesse vinculado à área da saúde, precisava cumprir os rituais. Também não culpo os entrevistados que, dando informações importantes ou não, concordaram em me receber, me ouvir e responder ao que lhes fosse conveniente. Assumo a responsabilidade pelo insucesso com as entrevistas. Eu sabia da importância dos encontros com os filhos, o sobrinho, os amigos, o editor. Os testemunhos deles eram fundamentais para a composição do retrato de Cyro.

Em Vidas ajenas: principia biographica, Leon Edel (1990, p. 46-47), autor de Henry James: a life, lembrou de James Boswell, de sua convivência com Samuel Johnson e de como isso influenciou a produção de The Life of Samuel Johnson. Tendo no horizonte o exemplo de Boswell, Edel classificou dois grupos de biógrafos: os que trabalham a partir da vida e os que chegam tarde. Os primeiros têm 
a oportunidade de dividir vivências, conversas e espaços com os biografados. Os outros não têm essa chance. Edel pensava que as melhores biografias eram aquelas "escritas por hombres que conocieron a sus sujetos y que los pintaron como el pintor pinta su pintura: dentro de una habitación, una calle, un paisaje, con un marco y en un contexto rico com sus millones de puntos de vínculos contemporâneos" (EDEL, 1990, p. 47). Conhecer o sujeito poderia resultar em um trabalho melhor, mas Leon Edel não via apenas prejuízos no caminho do biógrafo tardio. Nós, os tardios - me incluo no grupo -, contamos com uma vantagem: "la de una mayor objetividad obtenida de una perspectiva más amplia, una distancia en el tiempo" (EDEL, 1990, p. 47). A objetividade e a perspectiva ampla são relevantes no trato das ações do biografado, ainda mais quando se tem noção do conjunto das ações do biografado e se sabe das consequências de determinadas decisões. Entretanto, ser um biógrafo tardio implica um esforço para construir a imagem do sujeito. É claro que, na ausência do biografado, essa construção se dá através de documentos, fotografias, textos memorialísticos ou autobiográficos e depoimentos - do próprio sujeito e dos seus comensais.

O peso das entrevistas me perseguia já no início da tentativa biográfica. Não era só pela tentativa de compor a figura de Cyro que a questão me preocupava. Não tenho o dom da conversação e me afligia a possibilidade de que uma característica do biógrafo atrapalhasse em um desenho fiel do biografado. Além disso, eu tinha noção de que os testemunhos enriqueceriam a narração. Em Como escrever bem, William Zinsser (2017, p. 13), no capítulo dedicado às entrevistas, já sentenciara: "Seja qual for o seu gênero de não ficção, ele ganhará mais vida quanto mais 'citações' você conseguir introduzir no texto". Preocupado com o interesse do leitor, me importava o fato de dar "vida" à biografia de Cyro. Para isso, era preciso fazer a lição de casa, ir preparado aos encontros, não se inibir frente aos entrevistados, fazer as pessoas falarem. Essa parte me soava como a mais difícil - ainda que eu lembrasse de uma frase encorajadora de Zinsser (2017, p. 129): "O chamado homem comum adora quando alguém aparece para entrevistá-lo". Contudo, mesmo seguindo as instruções das duas orientadoras e as dicas de Zinsser, mesmo me esforçando para elaborar perguntas provocativas, mesmo tendo ciência de que as conversas valorizariam o trabalho, não tive sucesso. Não consegui fazer as pessoas fornecessem todas as informações que eu desejava.

Por causa disso, o leitor de Cyro Martins - os anos decisivos (1908-1951) pode achar que a biografia ficou muito presa aos documentos e à própria voz de Cyro. Esse não seria um erro de leitura, pois fiz raras citações às declarações dos entrevistados. $\mathrm{Na}$ falta de depoimentos prolíficos, decidi interpretar Cyro Martins a partir de suas palavras e de suas ações. De certa forma, eu desejava, assim como Antonio Hohlfeldt (2015, p. 44) na elaboração de Doce fera - fragmentos biográficos de Eva Sopher, "que a palavra da personagem estivesse o mais presente possível". Ao contrário de Hohlfeldt, eu não tinha como pedir ao biografado "breves textos rememorativos" (HOHLFELDT, 2015, p.44), mas podia recorrer à extensa produção de Cyro. Em diversas ocasiões, recorro às declarações de Cyro dadas a Abrão Slavutzky em Para início de conversa e às afirmações publicadas em entrevistas e prefácios de novas edições de suas obras. Também lanço mão de livros que carreguem tons autobiográficos (Mensagem errante, Um menino vai para o colégio, Rodeio - estampas e perfis, A dama do saladeiro - histórias vividas e andadas) e que citem amigos, companheiros de letras e colegas de profissão (Escritores gaúchos, Caminhos - ensaios psicanalíticos, Páginas soltas). Naturalmente, não deixo de lado as obras em que ele, seus familiares ou conhecidos surjam como personagens (Sombras na correnteza, Gaúchos no obelisco, $O$ professor).

É claro que, no trato com esses textos, não me abondam as dúvidas. Que imagem Cyro pretendia deixar? Até que ponto são confiáveis aquelas palavras? Parto de um princípio simples, senão simplório: um homem que escreve sobre si e que fala de si nas mais variadas oportunidades anseia por estar no centro das atenções, procura marcar, ser lembrado e permanecer. Percebo que Cyro Martins aspirava à perenidade e tinha consciência de que caminhos trilhar para atingir seu objetivo.

Também tive cuidado no trabalho com as outras fontes reunidas ao longo da escrita biográfica. O Delfos foi a principal origem dos documentos, das fotografias e das poucas correspondências utilizadas. Os acervos de João Otávio Nogueira Leiria, Moysés Vellinho e Manoelito de Ornellasforam de grande valia. Ainda na PUCRS, tiveram importância periódicos e obras da coleção Júlio Heinzelmann Petersen, localizadas no $6^{\underline{0}}$ andar da Biblioteca Central. Graças a essa coleção, tive a oportunidade de ler as primeiras edições dos livros de Cyro, o que muito me interessava, pois eu queria saber das vontades literárias do autor quando das publicações originais. Foram igualmente relevantes os históricos escolares que encontrei nas bibliotecas do Colégio Anchieta e da Faculdade de Medicina da UFRGS. Com eles, pude reconstruir partes da vida escolar e universitária de Cyro. Nos acervos do Correio do Povo, do Núcleo de Pesquisa em História da UFRGS (Coleção João Batista Marçal), do Hospital Psiquiátrico São Pedro, pude recolher informações relevantes sobre a figura intelectual de Cyro e sua carreira como funcionário público. Ainda foram pertinentes os catálogos da Revista do Globo 
(1929-1967) e da Província de São Pedro (1945-1957), organizados pela Professora Doutora Alice Therezinha Campos Moreira, e o fascículo Cyro Martins da série Autores gaúchos, publicada pelo Instituto Estadual do Livro do Rio Grande do Sul. É claro que Cyro Martins - os anos decisivos (1908-1951) deve muito ao primeiro texto biográfico sobre o sujeito: Cyro Martins - 100 anos: o homem e seus paradoxos, de Celito De Grandi e Nubia Silveira.

Não existem receitas para a formulação de um texto biográfico. Embora se encontrem obras de intenção didática como How to do biography: a primer, de Nigel Hamilton e Reflections on biography, de Paula Backsheider, e inúmeros prólogos instrutivos, tudo depende - do biografado, dos espaços de pesquisa, dos materiais, das circunstâncias. Ciente dessa dificuldade, escrevi os dez capítulos de Cyro Martins: os anos decisivos (1908-1995) tendo em mente as ideias de dois biógrafos/ teóricos: Leon Edel e Anna Caballé. Em Vidas ajenas: principia biographica, procurei lições sobre a relação com o biografado, a pesquisa em arquivos e o modo de narrar. Nos cursos de Caballé na PUCRS e nos encontros na Unidade de Estudos Biográficos da Universidade de Barcelona, tive orientações sobre as questões teóricas e éticas da biografia, a honestidade com o biografado e o leitor, a estrutura, a organização e as possibilidades do texto biográfico. Em Leon Edel e Anna Caballé busquei guias, mas nem sempre segui seus conselhos, pois temos pontos de vista diferentes, ocupamos lugares de fala diferentes e escrevemos biografias em circunstâncias diferentes.

$\mathrm{Na}$ tentativa de recompor a vida de Cyro Martins no período 1908-1951 e de acompanhar o processo de construção do personagem, desenvolvi o trabalho em onze partes. A primeira se intitula "Para início de conversa" e serve como um texto introdutório no qual esclareço o tema do trabalho, conto os caminhos que levaram à sua realização, indico os espaços de pesquisa percorridos, elucido a metodologia utilizada e faço uma breve menção sobre os textos teóricos que envolvem aspectos acerca da biografia.

A segunda, "O menino vai para um colégio de poucos" se desenvolve entre 1920 e 1925 - com referências a anos anteriores - traz aquilo que, aos meus olhos, é o ponto de inflexão na vida e na formação de Cyro Martins: a saída de Quaraí, em 1920, com 12 anos incompletos, e a ida para o Ginásio Anchieta, em Porto Alegre. Além da vida escolar de Cyro, são tratados, no capítulo, a solidão forçada, os esforços paternos para a educação dos filhos, a partida traumática do campo, o choque com a religiosidade, as aproximações com o pai e os distanciamentos em relação à mãe, as vivências como aluno externo e pobre que pulava de pensão em pensão, as férias no interior, as leituras, as tentativas de escrita, os amigos, a revolução de 1923 e suas consequências, a falta de dinheiro.

Em "Uma nova estrada na formação", abordo os anos que precederam a entrada de Cyro na Faculdade de Medicina, 1926-1927, os motivos que levaram à escolha por essa carreira, os anos de "doutoramento", 1928 1933, e os aspectos derivados deles - professores, aulas, colegas, formatura, dúvidas. Também voltei aos temas da situação financeira, das relações familiares, dos amigos, da literatura (com a leitura, a escrita e a publicação de alguns contos), da escrita e da solidão. Nesse capítulo, ainda trato de dois momentos importantes para a vida e a produção de Cyro - a Revolução de 1930 e a volta para casa depois de treze anos de ausência.

A quarta parte, "O homem grande na cidade pequena", é construída sobre o retorno de Cyro ao Cerro do Marco e as turbulências familiares e econômicas que ocorreram nessa época. Apesar de ser elaborado sobre um recorte temporal menor, de 1933 a 1935, o capítulo traz episódios relevantes para a história do biografado: a morte do pai e as mudanças que ela trouxe para os Martins, o início da prática médica, a estreia como escritor com a publicação de Campo fora, a perspectiva do casamento, o possível fim da solidão.

Em "O médico da vila", contemplo os anos de 1935 e 1936. Nesse período, Cyro experimenta os primeiros tempos do matrimônio e a relação com os sogros. Entre 1935 e 1936, ele continua a praticar a clínica médica, mas a situação em Quaraí não o satisfaz e é o principal motivo de suas inquietações. Atendimentos médicos e figuras humanas de Quaraí o marcam. A vontade de escrever não o abandona e a literatura se mostra um refúgio. Cyro tenta se inserir na vida da cidadezinha, mas o desejo de deixar Quaraí cresce. Uma dama uruguaia o aconselha a partir.

"Uma temporada carioca" destaca o ano de 1937 e a ida de Cyro para o Rio de Janeiro, a fim de ser aluno de Antônio Austregésilo e se especializar em Neurologia. Nessa temporada carioca, Cyro se aproxima da Editora Ariel e publica Sem rumo, primeiro de seus livros que aborda de maneira mais contundente o tema do gaúcho a pé. Ele deixou poucos rastros sobre 1937 e, na falta de documentos e depoimentos, são levantadas questões e hipóteses de como era a vida de Cyro e de Suely na então capital federal.

No capítulo "Outra vez Porto Alegre", focalizo 1938, 1939 e 1940. Durante esses três anos, Cyro se encaminhou profissionalmente, pois, em 1938, foi aprovado para o cargo de alienista no Hospital São Pedro. Logo depois, ele participou da fundação da Sociedade de Neurologia e Psiquiatria do Rio Grande do Sul e abriu seu primeiro consultório em Porto Alegre. Em 1939, pouco antes de a Segunda Guerra Mundial eclodir, Cyro publicou sua 
terceira obra, Enquanto as águas correm. O romance não se distanciava do gaúcho a pé, mas mostrava um autor bem mais preocupado com a construção dos personagens.

Na parte "Depois das tempestades", privilegio os anos 1941-1942 e destaco dois importantes acontecimentos na vida de Cyro: o nascimento de Maria Helena, a primeira filha, e a publicação de outro romance, Mensagem errante. Aparentemente, entre os anos decisivos, esse é o período de maior tranquilidade pelo qual Cyro passa: encontra a estabilidade financeira com o cargo no Hospital São Pedro, mantém um consultório, se torna pai depois de quase seis anos de casamento e se insere no sistema literário do Rio Grande do Sul.

Em "Um escritor da Província", percorro 1943, 1944 e 1945. Em 1943, Cyro soube da possibilidade de ir fazer a formação psicanalítica em Buenos Aires e a ideia o perseguiu até se tornar uma realidade, tempos depois. 1944 foi um ano frutífero para Cyro. Com a publicação de Porteira fechada, seu nome, já reconhecido na cena literária gaúcha, ganhou outro estofo. A partir do novo livro, sua fortuna crítica aumentou consideravelmente e sua voz começou a ser mais ouvida entre os intelectuais da província. Também em 1944, nasceu Cecília, a segunda filha. Em 1945, quando tudo parecia confluir para uma vida feliz, as tormentas familiares voltaram.

Em "Sombras no caminho", trabalho com um recorte temporal maior (1946-1951). A vida de Cyro passou por muitas reviravoltas nesses anos: a separação de Suely, os conflitos com a sogra, o casamento com Zaira Meneghello, a partida para Buenos Aires. Há névoa e lacunas sobre esses episódios, boa parte deles não é rastreável. Sabe-se que aconteceram, mas é difícil de datá-los e não se tem acesso a um número considerável de documentos. Apesar de não editar livros durante o período, Cyro continua a se envolver com a escrita - os contos e os artigos publicados em periódicos indicam isso. No entanto, o passo mais significativo dessa época é dado em direção à psicanálise.

No "Epílogo", retomo alguns aspectos da pesquisa e fecho os anos decisivos do biografado.

Nos capítulos que compõem Cyro Martins - os anos decisivos (1908-1951), não ultrapasso os limites do biógrafo. Tento tratar o biografado com o máximo de honestidade, procurando não o santificar nem o demonizar. Cada vez que sentei para escrever sobre Cyro, pensei que ele era um homem e, como tal, tinha atitudes boas, não tão boas e más. Acredito ser difícil alguém se aventurar em um desafio biográfico sem aquele laço "tan elusivo y peligroso como indispensable, que liga al biógrafo y al biografiado: la empatía" (BURDIEL; FOSTER, 2015, p. 14). Por isso, também tento me colocar no seu lugar e refletir sobre o que eu faria se estivesse em algumas das situações enfrentadas por ele.

$\mathrm{Na}$ escrita de parte da vida de Cyro Martins, não trabalhei apenas com a honestidade em relação ao biografado. Em todos os momentos, pensei em um leitor hipotético e no contrato que assinaria com ele. Por isso, deixo claro que Cyro Martins - os anos decisivos (19081951) é um ponto de vista sobre um homem; um texto que trabalha com fatos e possibilidades, não preenche todas as lacunas de uma existência e não se pretende definitivo.

\section{Referências}

BURDIEL, Isabel; FOSTER, Roy. Introducción. La historia biográfica en Europa: nuevas perspectivas. Zaragoza: Instituición Fernando el Católico, 2015. p. 9-14.

CABALLÉ, Anna. ¿Dónde están las gafas? La biografia, entre la metodología y la casuística. 2015. Disponível em: <http:// www.ub.edu/ueb/?p=223>. Acesso em: 08 de dezembro de 2017.

CASTELLO, José. Carta a um jovem biógrafo. VOX, Porto Alegre, v. 1, n. 6, p. 51-55, abr. 2001.

DE GRANDI, Celito; SILVEIRA, NÚBIA. Cyro Martins - 100 anos: o homem e seus paradoxos. Cachoeira do Sul: Defender, 2008

DOSSE, François. O desafio biográfico: escrever uma vida. Trad. Gilson César Cardoso de Souza. São Paulo: EDUSP, 2015.

EDEL, Leon. Vidas ajenas: principia biographica. Buenos Aires: Fondo de Cultura Económica, 1990.

GUSDORF, Georges. Les ecritures du moi. Paris: Odile Jacob, 1991.

HOHLFELDT, Antonio. Exercícios biográficos: arqueologia cultural. In: GUTFREIND, Cristiane Freitas (Org.). Narrar o biográfico: a comunicação e a diversidade da escrita. Porto Alegre: Sulina, 2015. p. 41-79.

MARTINS, Cyro; SLAVUTZKY, Abrão. Para início de conversa. Porto Alegre: Movimento, 1990.

RICOEUR, PAUL. Tempo e narrativa III. Trad. Claudia Berliner. São Paulo: Martins Fontes, 2010

WOOLF, Virginia. La nueva biografía. Memoria: revista de estudios biográficos, Barcelona, n. 3, p. 194-198, 2007.

ZINSSER, William. Como escrever bem: o clássico manual americano de escrita jornalística e de não ficção. Trad. Bernardo Ajzenberg. São Paulo: Três Estrelas, 2017.

Recebido: 15/12/2017

Aprovado: 20/04/2018

Contato:

Fábio Varela Nascimento <fv.nasci@gmail.com> 